OPEN ACCESS

Approved by: Frontiers Editorial Office, Frontiers Media SA, Switzerland

*Correspondence:

Qingwei Meng mawei@126.com

Yanjing $L$

liyanjing_hum@126.com

Specialty section: This article was submitted to

Molecular Diagnostics and

Therapeutics,

a section of the journal

Frontiers in Molecular Biosciences

Received: 14 January 2021

Accepted: 09 February 2021

Published: 13 April 2021

Citation:

Gan J, Meng Q and Li Y (2021) Corrigendum: Systematic Analysis of Expression Profiles and Prognostic Significance for FAM83 Family in Non-

Small-Cell Lung Cancer.

Front. Mol. Biosci. 8:653454.

doi: 10.3389/fmolb.2021.653454

\section{Corrigendum: Systematic Analysis of Expression Profiles and Prognostic Significance for FAM83 Family in Non-Small-Cell Lung Cancer}

\author{
Junqing Gan ${ }^{1}$, Qingwei Meng ${ }^{1 *}$ and Yanjing $L i^{2 *}$
}

'Department of Medical Oncology, Harbin Medical University Cancer Hospital, Harbin, China, ${ }^{2}$ Department of Gastrointestinal Oncology, Harbin Medical University Cancer Hospital, Harbin, China

Keywords: non-small-cell lung cancer, FAM83 family, bioinformatics analysis, biomarker, prognostic value

\section{A corrigendum on}

Systematic Analysis of Expression Profiles and Prognostic Significance for FAM83 Family in Non-Small-Cell Lung Cancer

by Gan, J., Li, Y., and Meng, Q. (2020). Front. Mol. Biosci. 7:572406. doi:10.3389/fmolb.2020.572406

In the published article, there were errors in affiliations 1 and 2 and the order of corresponding authors. Instead of "Junqing $\mathrm{Gan}^{1}$, Yanjing $\mathrm{Li}^{1, *}$ and Qingwei Meng ${ }^{2, *}{ }^{1}$ Department of Gastrointestinal Oncology, Harbin Medical University Cancer Hospital, Harbin, China ${ }^{2}$ Department of Medical Oncology, Harbin Medical University Cancer Hospital, Harbin, China," it should be "Junqing Gan ${ }^{1}$, Qingwei Meng ${ }^{1, *}$ and Yanjing $\mathrm{Li}^{2, *}{ }^{1}$ Department of Medical Oncology, Harbin Medical University Cancer Hospital, Harbin, China ${ }^{2}$ Department of Gastrointestinal Oncology, Harbin Medical University Cancer Hospital, Harbin, China."

The authors apologize for these errors and state that this does not change the scientific conclusions of the article in any way. The original article has been updated.

Copyright $(2021$ Gan, Meng and Li. This is an open-access article distributed under the terms of the Creative Commons Attribution License (CC BY). The use, distribution or reproduction in other forums is permitted, provided the original author(s) and the copyright owner(s) are credited and that the original publication in this journal is cited, in accordance with accepted academic practice. No use, distribution or reproduction is permitted which does not comply with these terms. 